\title{
Compact Band-Pass Filter Using Modified $\Omega$-shaped Resonator and Source Load Coupling for Transmission Zero Improvement
}

\author{
Naveen MISHRA ${ }^{1}$, Raghvendra Kumar CHAUDHARY ${ }^{2}$ \\ ${ }^{1}$ Dept. of Communication Engineering, School of Electronics Engineering, Vellore Institute of Technology, Vellore \\ Tamil Nadu 632014, Tamil Nadu, India \\ ${ }^{2}$ Dept. of Electronics Engineering, Indian Institute of Technology (Indian School of Mines) Dhanbad, \\ Dhanbad 826004, Jharkhand, India
}

naveenmishra.ece@gmail.com,raghvendra.chaudhary@gmail.com

Submitted May 31, 2020 / Accepted October 27, 2020

\begin{abstract}
This article investigates a compact band-pass filter using modified $\Omega$-shaped resonator and source load coupling for transmission zero improvement. In this article, source load coupling has been used to improve the insertion loss response and a number of transmission zeros in the upper stop-band, so that the chance of interference from adjacent wireless bands can be reduced. In order to determine the metamaterial characteristics for the designed filter structure dispersion diagram and vectored electric-field with no phase variation has been illustrated. The simulated and measured $3 d B$ fractional bandwidth for the designed filter structure is $26.05 \%$ and $26.12 \%$ at the center frequency of 2.38 and $2.33 \mathrm{GHz}$ respectively. It offers compactness with an electrical footprint area of $0.245 \lambda_{g} \times 0.201 \lambda_{g}$, where $\lambda_{g}$ is the guided wavelength at the center frequency of $2.33 \mathrm{GHz}$. The presented filter structure seems a potential candidate for different wireless applications such as Bluetooth (2.4-2.48 GHz), WLAN/WiFi (2.4-2.49 GHz) and Wi-MAX (2.5-2.69 GHz).
\end{abstract}

\section{Keywords}

Compact, bandpass filter, zeroth order resonance, source-load coupling

\section{Introduction}

The recent development in wireless communication system requires compact band-pass filter with improved insertion loss performance [1]. In early years, several attempts have been utilized to reduce the filter size. For this purpose, in the year of 1998, Yu et al. [2] utilized open loop resonators coupled with crossing lines. Further, in the year of 2004, Allison filed a U.S. patent on compact edge coupled filter. In this approach the parallel edge coupled filter has been modified into multiple coupled resonators [3]. Size of the resonator of these filters is nearly half of the guided wavelength which restricts the compactness. In order to overcome the above mentioned problem, a new approach of MTMs (metamaterials) came into existence.

MTMs are artificially designed materials with unique properties of negative permittivity and permeability [4]. Several efforts have been made which utilizes the concept of MTMs to improve the response of compact filters [5-10]. In [5] Luo et al. utilized a complimentary split ring based resonator to design a bandpass filter with wideband and improved selectivity. A CPW fed compact bandpass filter with controllable transmission zeros (TZs) by separated electric and magnetic coupling has been discussed in [6]. In [7], Tang et al. utilized meandered loop hexagon line to reduce the size of the filter. Further, in literature [9], a compact dual band bandpass filter has been designed and investigated. Among both the filtering bands one band is claimed with the modified complementary split ring resonator and another with interdigital capacitor. In the year of 2019, Choudhary et al. [10] utilized folded coupled line and open-circuited L-shaped strip to design a compact dual band bandpass filter. Another approach to design a bandpass filter with substrate integrated waveguide has been reported in [11].

In this article, a compact bandpass filter using modified $\Omega$ shaped resonator and source load coupling for TZ improvement has been designed and discussed. In order to design this filter structure the concept of CRLH-TL has been utilized. Designed filter structure is configured with series gap and shunted via to offer left handed capacitance and left handed inductance. Further source load coupling improves insertion loss performance and introduces additional $\mathrm{TZ}$ in the upper stopband. 


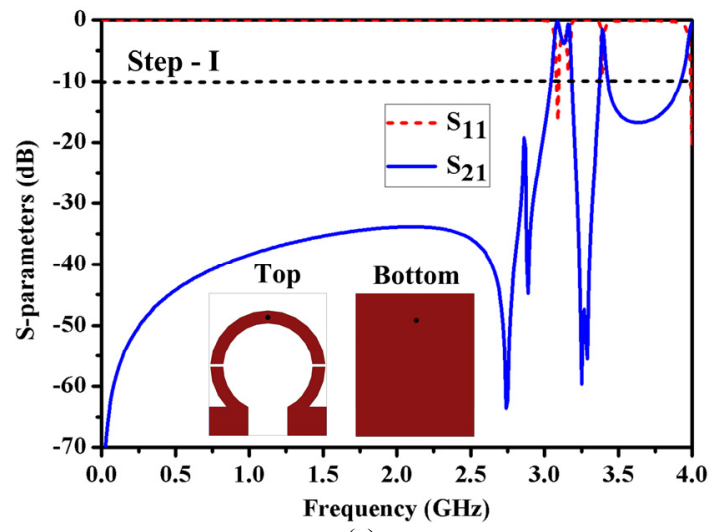

(a)

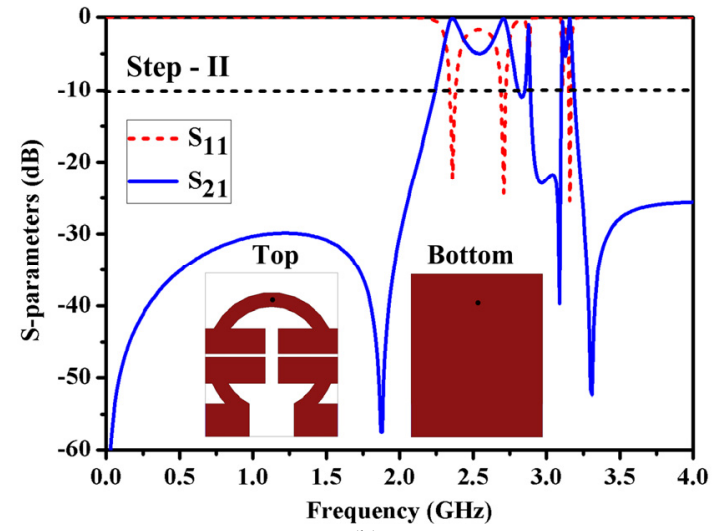

(b)

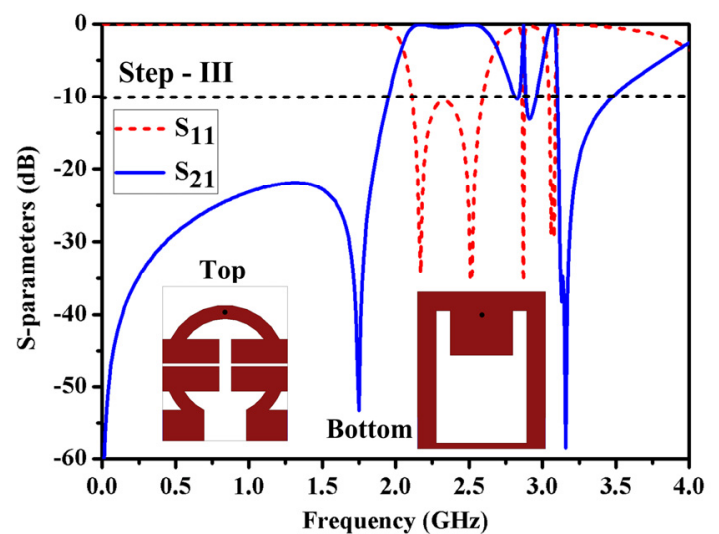

(c)

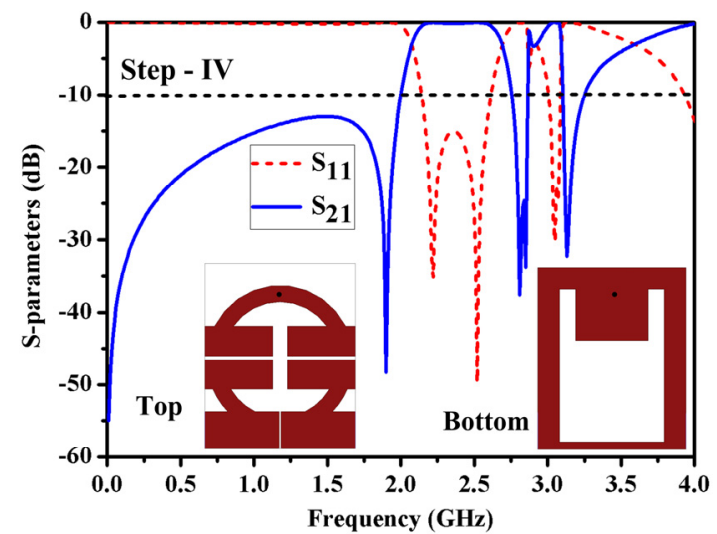

(d)

Fig. 1. Distinct developing stages of designed bandpass filter.

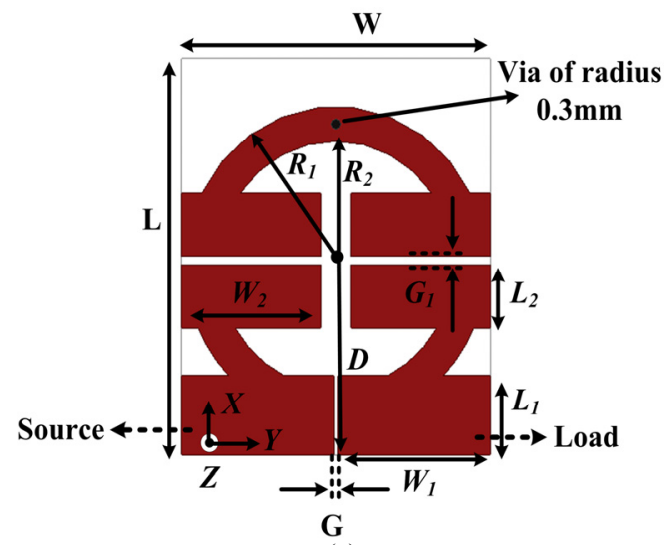

(a)

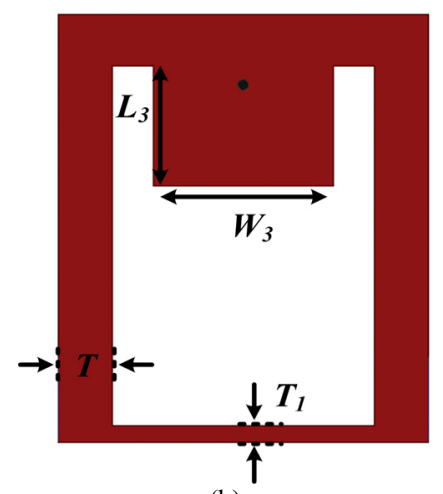

(b)

Fig. 2. Geometrical configuration of the designed bandpass filter. All proportions are in mm: $L=25, L_{1}=5, L_{2}=4$, $L_{3}=7, T=3, T_{1}=1, G=0.3, G_{1}=0.5, D=12, R_{1}=$ $10, R_{2}=7.8, W=20.5, W_{1}=10.1, W_{2}=9.25, W_{3}=10$.

\section{Design and Analysis for Designed Bandpass Filter}

Design procedure of the proposed filter structure starts from the concept of CRLH-TL. It is a well-known factor that the perfect right-handed transmission line has low-pass nature and the perfect left-handed transmission line has high-pass nature. The CRLH-TL is the combination of perfect right-handed and perfect left-handed transmission line. From the above discussion it can be concluded that the CRLH-TL has bandpass nature. The selection of modified $\Omega$-shaped resonator has been done to achieve more compactness [4]. Initially, with the use of via and series gap simplified CRLH-TL based structure has been created, shown in Fig. 1(a).

To improve the response, patches are introduced which modify the associated series inductance and capacitance and offer two resonance peaks with negligible bandwidth, as shown in Fig. 1(b). Further the ground plane has been modified to improve the matching and allows a wideband response, Fig. 1(c). In order to achieve a desired response, filter dimensions have been optimized. For this purpose Ansys HFSS 13.0 three dimensional electromagnetic full wave simulator have been used. After that the 
source to load coupling has been done to improve the insertion loss response, depicted in Fig. 1(d).

The geometrical configuration of the designed filter structure with its proportions has been mentioned in Fig. 2 . The equivalent circuit diagram for the designed filter structure, Fig. 3(a), have left-handed capacitance $\left(C_{\mathrm{L}}\right)$ which is modelled by the separation between patches $\left(G_{1}\right)$. The feed line and patches represent right-handed inductance $L_{\mathrm{R} 1}$ and $L_{\mathrm{R} 2}$ respectively. Further the separation between source and load feed lines $(G)$ originates one coupling capacitance $\left(C_{\mathrm{C}}\right)$ in series. Left-handed inductance $\left(L_{\mathrm{L}}\right)$ is associated with via and bottom ground plane structure and the separation between top and bottom structure separated by substrate creates right-handed capacitance $\left(C_{\mathrm{R}}\right)$. In order to investigate the MTM property of the designed filter structure Bloch-Floquet theorem has been exploited. According to this the dispersion relation can be expressed in terms of immittances of equivalent circuit diagram

$$
\beta(\omega) d=\cos ^{-1}\left(1+Z_{\mathrm{s}}(\omega) Y_{\mathrm{p}}(\omega)\right) .
$$

Here $d, Z_{\mathrm{s}}(\omega), Y_{\mathrm{p}}(\omega)$ and $\beta(\omega)$ are the physical length of the unit cell, series impedance, shunt admittance and propagation constant respectively.

$$
\begin{aligned}
& Z_{\mathrm{s}}(\omega)=Z_{\mathrm{sa}}(\omega)+Z_{\mathrm{sb}}(\omega), \\
& Z_{\mathrm{sa}}(\omega)=\mathrm{j} \omega L_{\mathrm{R} 1}, \\
& Z_{\mathrm{sb}}(\omega)=Z_{\mathrm{sc}} \| Z_{\mathrm{sd}}, \\
& Z_{\mathrm{sc}}(\omega)=\mathrm{j} \omega L_{\mathrm{R} 2}+\frac{1}{\mathrm{j} \omega C_{\mathrm{L}}}=\frac{1-\omega^{2} L_{\mathrm{R} 2} C_{\mathrm{L}}}{\mathrm{j} \omega C_{\mathrm{L}}}, \\
& Z_{\mathrm{sd}}(\omega)=\frac{1}{\mathrm{j} \omega C_{\mathrm{C}}}, \\
& Z_{\mathrm{sb}}(\omega)=\frac{1-\omega^{2} L_{\mathrm{R} 2} C_{\mathrm{L}}}{\mathrm{j} \omega\left[\left(C_{\mathrm{C}}+C_{\mathrm{L}}\right)-\omega^{2} C_{\mathrm{C}} C_{\mathrm{L}} L_{\mathrm{R} 2}\right]}, \\
& Y_{\mathrm{p}}(\omega)=\mathrm{j} \omega C_{\mathrm{R}}+\frac{1}{\mathrm{j} \omega L_{\mathrm{L}}}=\frac{1-\omega^{2} L_{\mathrm{L}} C_{\mathrm{R}}}{\mathrm{j} \omega L_{\mathrm{L}}} .
\end{aligned}
$$

Condition for the occurrence of resonance is given in (4)

$$
\beta(\omega) d=n \pi, n=0, \pm 1, \pm 2, \ldots \ldots, \pm(N-1) .
$$

Equations (1) and (4) can be utilized to calculate the dispersion relation and zeroth order resonance (ZOR). Dispersion relation can also be expressed in terms of S-parameters [12].

Simulated dispersion graph has been plotted and shown in Fig. 3(b). Since the ZOR is the point at which $\beta d$ become zero means ZOR supports infinite wave propagation at a non-zero frequency. So it is evident from the graph that the ZOR occurred at the frequency of $2.21 \mathrm{GHz}$. Additionally, the graph has two sections those are separated by ZOR, i.e. LH-region and $\mathrm{RH}$-region. $\mathrm{LH}$ region extended from 2 to $2.21 \mathrm{GHz}$ while $\mathrm{RH}$-region lies from 2.21 to $2.72 \mathrm{GHz}$. In order to validate the equivalent circuit

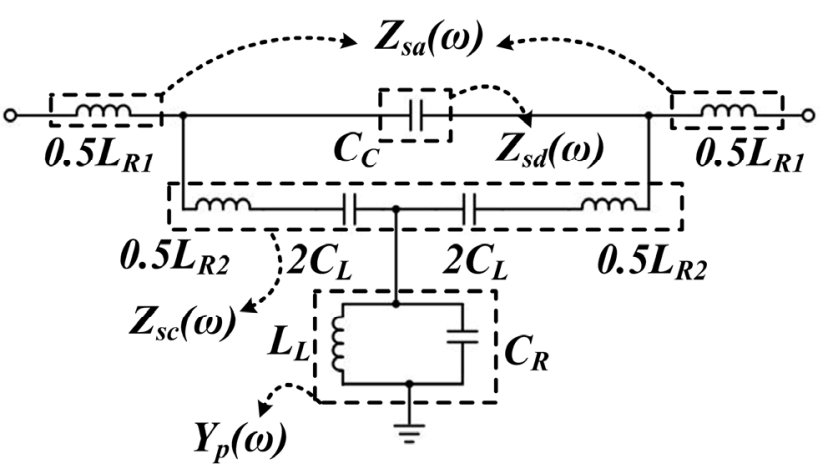

(a)

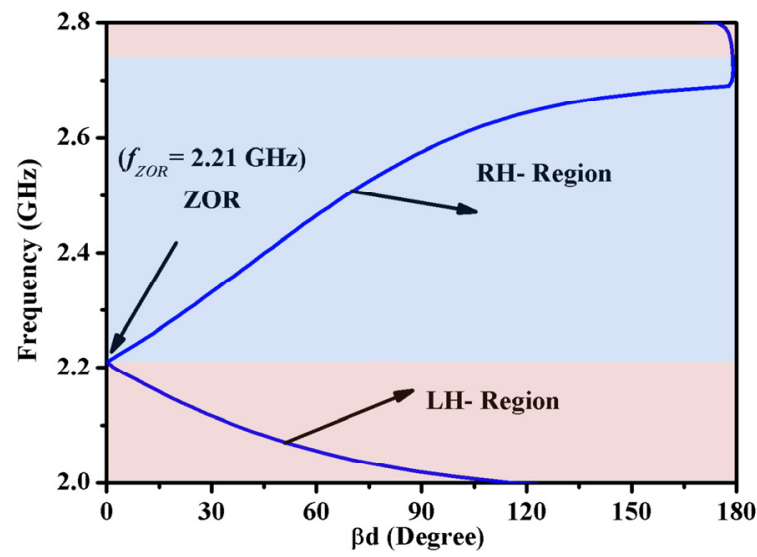

(b)

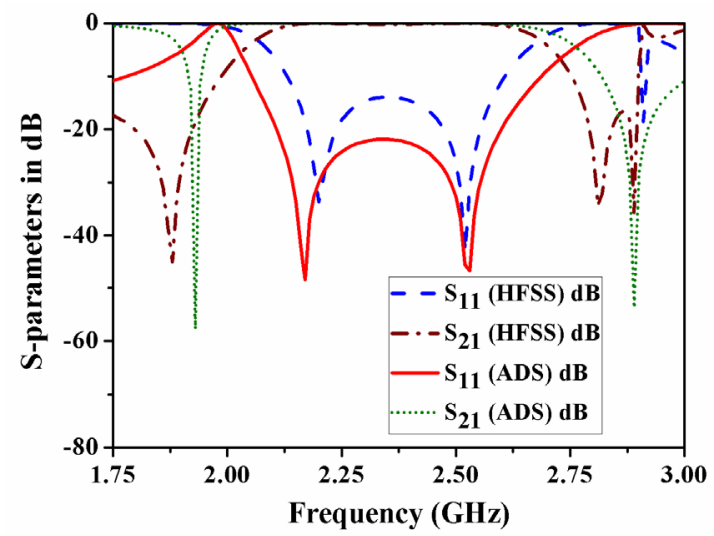

(c)

Fig. 3. (a) Equivalent circuit diagram; (b) dispersion diagram (c) comparison between HFSS and ADS S-parameters.

model of Fig. 3(a), ADS circuit simulator has been utilized. The extracted values are $L_{\mathrm{R} 1}=5.18 \mathrm{nH}, L_{\mathrm{R} 2}=31.72 \mathrm{nH}$, $C_{\mathrm{C}}=2.07 \mathrm{pF}, \quad C_{\mathrm{L}}=0.24 \mathrm{pF}, \quad L_{\mathrm{L}}=10.73 \mathrm{nH}$ and $C_{\mathrm{R}}=$ $0.87 \mathrm{pF}$. Based on extracted values the S-parameter curve has been plotted and compared with the HFSS full wave simulator S-parameter response for the designed filter structure, shown in Fig. 3(c). It has been evident from Fig. 3(c) that both the S-parameter responses are having similar pattern.

Further, ZOR has been also confirmed by the no phase variation graph of vectored E (electric) field, shown in Fig. 4. It can be clearly observed that the vectored Efield has almost no phase variation on the patches and feed lines, hence confirms ZOR [13]. 


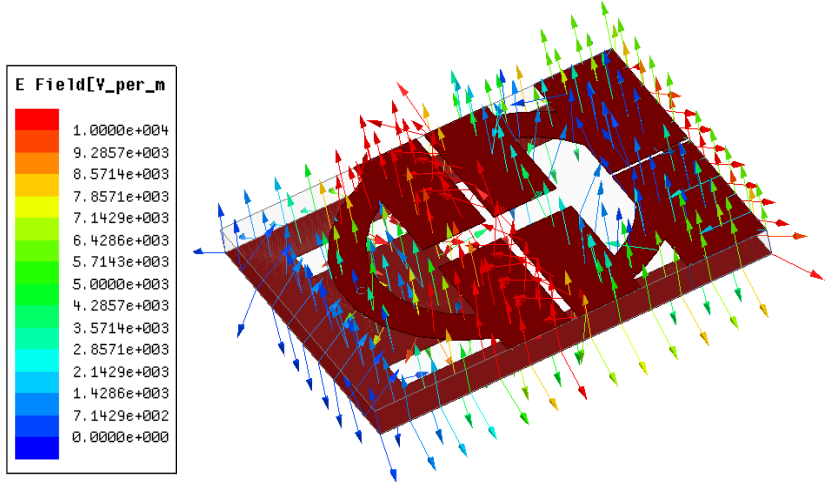

Fig. 4. Vectored E-field pattern on the designed bandpass filter structure.

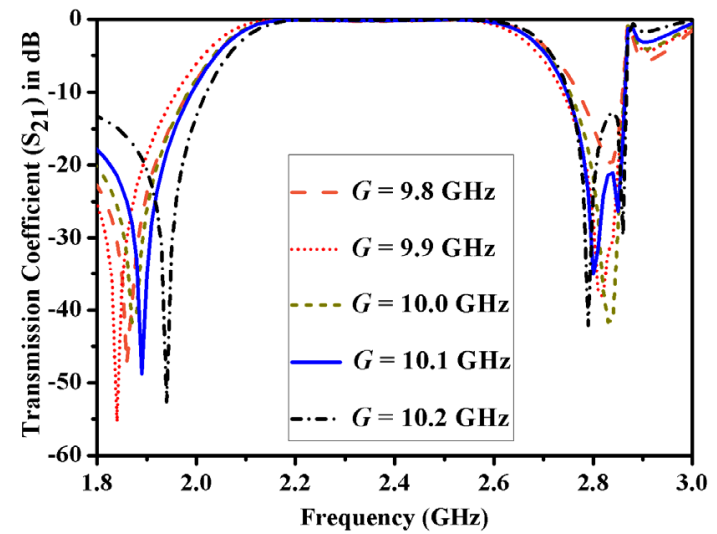

(a)

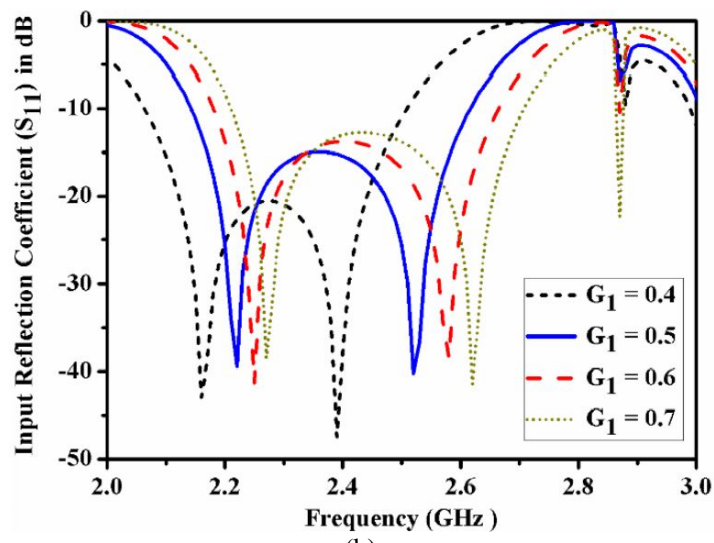

(b)

Fig. 5. Different parametric variations. (a) $S_{21}$ at distinct value of $G$, (b) $S_{11}$ at distinct value of $G_{1}$.

Figure 5(a) shows the transmission coefficient graph at various values of $G$ (gap between source and load feedlines). Decrement in $G$ corresponds to stronger coupling between source and load treated as port-1 and port-2, which results into an additional transmission zero in the upper stopband of the filter response. It can be explained by the phase difference between the RF signal propagates from $\Omega$ shaped path and source load coupling path at the port-2 [14]. Figure 5(b) depicts the input reflection coefficient plot at distinct values of $G_{1}$. It is evident that by increasing $G_{1}$ (separation between patches) both the resonance frequencies are shifted towards higher frequencies.

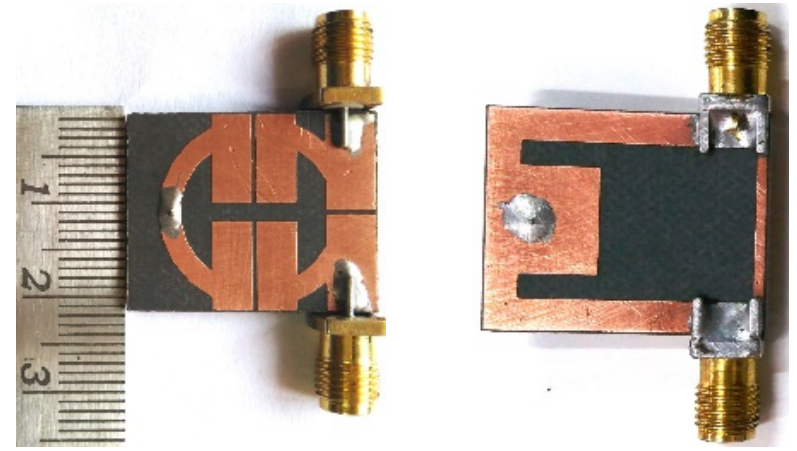

Fig. 6. Fabricated prototype of the designed bandpass filter structure.

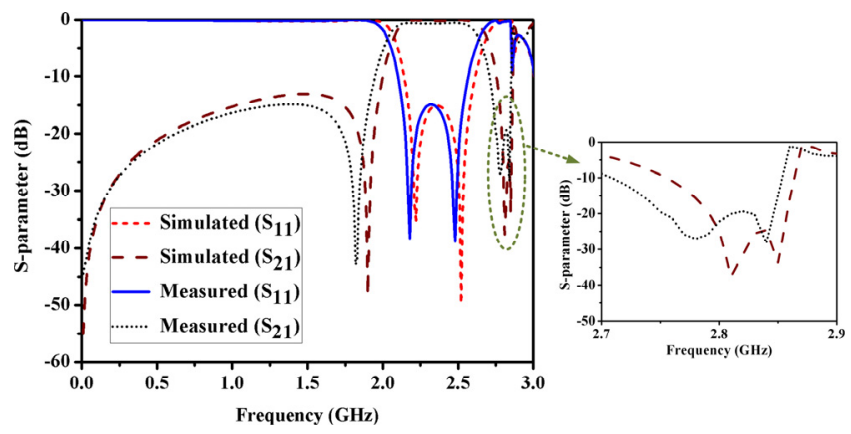

Fig. 7. Simulated and measured S-parameter response for the designed filter.

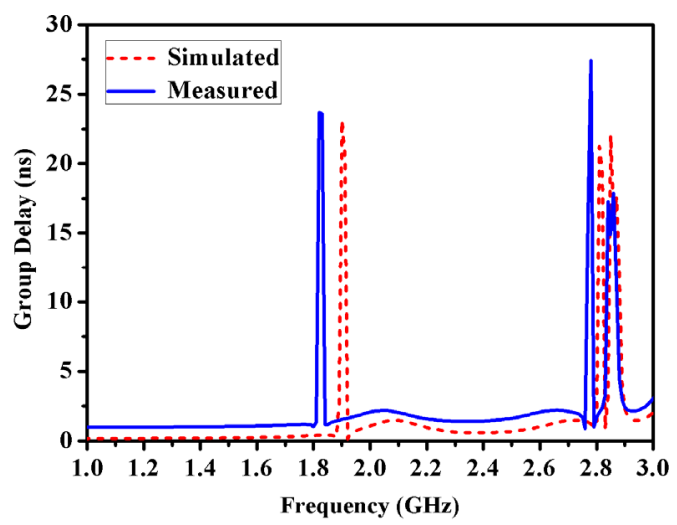

Fig. 8. Simulated and measured group delay response of the designed bandpass filter.

\section{Result and Discussion}

The top and bottom view of the fabricated proto-type of the designed filter structure has been shown in Fig. 6. It is printed on the Roger RT-Duroid 5880 substrate $\left(\varepsilon_{\mathrm{r}}=2.2\right)$ of thickness $1.58 \mathrm{~mm}$. The simulated and measured S-parameters for the designed filter structure have been depicted in Fig. 7. It is observed that the simulation and measured S-parameters follow approximately same pattern. The deviation in simulated and measured S-parameters may be because of the substrate non-uniformity, soldering losses, fabrication tolerance. It may be also because of the uncertainty of the relative dielectric constant and the height of the substrate [15]. 


\begin{tabular}{|c|c|c|c|c|c|}
\hline & $\begin{array}{c}\text { CF } \\
(\mathrm{GHz})\end{array}$ & $\begin{array}{c}-3 \mathrm{~dB} \text { FBW } \\
(\%)\end{array}$ & $\begin{array}{c}\text { IL } \\
(\mathrm{dB})\end{array}$ & $\begin{array}{c}\text { RL } \\
(\mathrm{dB})\end{array}$ & $\begin{array}{c}\text { CES } \\
\left(\lambda_{0} \times \lambda_{0)}\right.\end{array}$ \\
\hline $\begin{array}{c}\text { This } \\
\text { work }\end{array}$ & 2.33 & 26.12 & 0.54 & $>14.90$ & $0.245 \times 0.201$ \\
\hline$[5]$ & 5 & 75 & 0.4 & 11.5 & $0.476 \times 0.181$ \\
\hline$[6]$ & 2.28 & --- & 1.58 & $>14$ & $0.26 \times 0.36$ \\
\hline$[7]$ & 2.45 & 3.5 & 2.3 & $>15$ & $0.26 \times 0.30$ \\
\hline$[8]$ & 3.1 & 20.9 & 2.55 & $>11$ & $0.55 \times 0.30$ \\
\hline$[11]$ & 1.684 & 4 & 1.3 & $>22$ & $0.21 \times 0.63$ \\
\hline
\end{tabular}

Tab. 1. Performance comparison of the proposed filter structure with the previously designed filters $(\mathrm{CF}=$ center frequencies, FBW $=3 \mathrm{~dB}$ fractional bandwidth, $\mathrm{IL}=$ insertion loss, $\mathrm{RL}=$ return loss, $\mathrm{CES}=$ circuit electrical size).

The designed filter structure offers $3 \mathrm{~dB}$ simulated and measured fractional bandwidth of $26.05 \%$ and $26.12 \%$ centered at 2.38 and $2.33 \mathrm{GHz}$ respectively. It offers compactness with electrical footprint area of $0.245 \lambda_{\mathrm{g}} \times 0.201 \lambda_{\mathrm{g}}$, where $\lambda_{\mathrm{g}}\left(\varepsilon_{\mathrm{eff}}=1.6, \lambda_{\mathrm{g}}=101.78 \mathrm{~mm}\right)$ is the guided wavelength at the center frequency of $2.33 \mathrm{GHz}$. In order to calculate the effective permittivity $\left(\varepsilon_{\text {eff }}\right)$ and guided wavelength $\left(\lambda_{\mathrm{g}}\right)$ equations (5) and (6) have been used respectively.

$$
\begin{gathered}
\varepsilon_{\text {eff }}=\frac{\varepsilon_{\mathrm{r}}+1}{2}+\frac{\varepsilon_{\mathrm{r}}-1}{2}\left\{\sqrt{1+12\left(\frac{H}{W}\right)}\right\}^{-1}, \\
\lambda_{\mathrm{g}}=\frac{\lambda}{\sqrt{\varepsilon_{\text {eff }}}}=\frac{c}{f \sqrt{\varepsilon_{\text {eff }}}}
\end{gathered}
$$

where, $H$ and $W$ stand for thickness of substrate and width of the microstrip-line respectively [15]. On the basis of above two equations the calculated value of effective dielectric constant and guided wavelength are 1.6 and $101.78 \mathrm{~mm}$ respectively.

Additionally, it offers maximum simulated and measured transmission coefficient of $-0.03 \mathrm{~dB}$ and $-0.54 \mathrm{~dB}$ along with simulated and measured input reflection coefficient better than $-15 \mathrm{~dB}$ and $-14.90 \mathrm{~dB}$ in the complete working band. Figure 8 shows the simulated and measured group delay plot for the designed structure which is almost flat throughout the band. Flat response indicates transmission with least distortion. Average simulated and measured group delay for the designed filter structure is 0.91 and $1.71 \mathrm{nsec}$ respectively. Table 1 presents a comparison chart of this work with previously published works.

\section{Conclusion}

In this article, a compact band-pass filter using modified $\Omega$-shaped resonator and source load coupling for transmission zero improvement has been illustrated. Designed filter structure provides compactness with overall electrical size of $0.245 \lambda_{\mathrm{g}} \times 0.201 \lambda_{\mathrm{g}}$, where $\lambda_{\mathrm{g}}$ is the guided wavelength at the center frequency of $2.33 \mathrm{GHz}$. In this filter design source to load coupling has been done to improve transmission coefficient and generate two TZs in the upper stop-band. Further, the dispersion analysis has been performed to investigate the MTM property of the designed filter structure.

\section{Acknowledgement}

The authors would like to thank Mr. Dilip Choudhary, Research Scholar at Indian Institute of Technology (Indian School of Mines) Dhanbad, India, for his assistance to improve the technical content and language of this manuscript.

\section{References}

[1] POZAR D. M. Microwave Engineering. $4^{\text {th }}$ ed. USA: Wiley, 2011. ISBN: 978-0-470-63155-3

[2] ZHANG, J., GU, J.-Z., CUI, B., et al. Compact and harmonic suppression open-loop resonator bandpass filter with tri-section SIR. Progress In Electromagnetics Research, 2007, vol. 69, p. $93-$ 100. DOI: 10.2528 /PIER06120702

[3] ALlisON, R. C. Compact edge coupled filter. United States Patent 6762660 B2, July 2004

[4] CALOZ, C., ITOH, T. Electromagnetic Metamaterials: Transmission Line Theory and Microwave Applications. USA: Wiley, 2006. DOI:10.1002/0471754323

[5] LUO, X., QIAN, H., MA, J-G., et al. Wideband bandpass filter with excellent selectivity using new CSRR-based resonator. Electronics Letters, 2010, vol. 46, no. 20, p. 1390-1391. DOI: 10.1049/el.2010.1817

[6] XIAO, J. K., ZHU, M., LI, Y., et al. Coplanar waveguide bandpass filters with separated electric and magnetic couplings. Electronics Letters, 2016, vol. 52, no. 2, p. 122-124. DOI: $10.1049 / \mathrm{el} .2015 .3112$

[7] TANG, M.-C., SHI, T., TAN, X. A novel triple-mode hexagon bandpass filter with meander line and central-loaded stub. Microwave and Optical Technology Letters, 2016, vol. 58, no. 1, p. 9-12. DOI: $10.1002 / \mathrm{mop} .29483$

[8] FENG, W., GAO, X., CHE, W. Bandpass filters with improved selectivity based on dual-mode ring resonators. Progress In Electromagnetics Research Letters, 2015, vol. 56, p. 1-7. DOI: 10.2528/PIERL15072609

[9] CHOUDHARY, D. K., CHAUDHARY, R. K. A compact CPWbased dual-band filter using modified complementary split ring resonator. AEU - International Journal of Electronics and Communications, 2018, vol. 89, p. 110-115. DOI: 10.1016/j.aeue.2018.03.032

[10] CHOUDHARY, D. K., CHAUDHARY, R. K. Compact lowpass and dual-band bandpass filter with controllable transmission zero/center frequencies/passband bandwidth. IEEE Transactions on Circuits and Systems II: Express Briefs, 2019, vol. 67, no. 6, p. 1044-1048. DOI: $10.1109 /$ TCSII.2019.2931446

[11] NWAJANA, A. O., DAINKEH, A., YEO, K. S. K. Substrate integrated waveguide (SIW) bandpass filter with novel microstripCPW-SIW input coupling. Journal of Microwaves, 
Optoelectronics and Electromagnetic Applications, 2017, vol. 16, p. 393-402. DOI: 10.1590/2179-10742017v16i2793

[12] WANG, K., TANG, H., WU, R., et al. A novel compact dual-band filter based on quarter-mode substrate integrated waveguide and complementary split ring resonator. Microwave and Optical Technology Letters, 2016, vol. 58, no. 11, p. 2704-2707. DOI: 10.1002/mop.30131

[13] MISHRA, N., CHAUDHARY, R. K. A miniaturized ZOR antenna with enhanced bandwidth for Wi-MAX applications. Microwave and Optical Technology Letters, 2016, vol. 58, no. 1, p. 71-75. DOI: $10.1002 /$ mop.29494

[14] LIAO, C. K., CHANG, C.-Y. Design of microstrip quadruplet filters with source-load coupling. IEEE Transactions on Microwave Theory and Techniques, 2005, vol. 53, no. 7, p. 2302-2308. DOI: 10.1109/TMTT.2005.850442

[15] MABROUK, M., BOUSBIA, L. Study and enhanced design of RF dual band bandpass filter validation and confirmation of experimental measurements. Circuits and Systems, 2011, vol. 2, p. 293-296. DOI: $10.4236 /$ cs.2011.24041

\section{About the Authors...}

Dr. Naveen MISHRA was born in Deoria (Uttar Pradesh), India on October 04, 1990. Currently, he is working as an assistant professor (senior) in the School of Electronics Engineering, Vellore Institute of Technology, VIT University Vellore. He joined the VIT University in May 2019. $\mathrm{He}$ joined the Department of Electronics Engineering, Indian Institute of Technology (Indian School of Mines) Dhanbad, in January 2014, as a Junior Research Fellow, where he worked as a Senior Research Fellow from January 2016 to May 2019. He completed his Doctorate Degree from the Indian Institute of Technology (Indian School of Mines) Dhanbad. He received the B. Tech. degree in Electronics \& Communication Engineering from Uttar Pradesh Technical University, Lucknow in 2010. He has been worked as an assistant professor from August 2011 to January 2014 in ABSS I.T. Meerut affiliated with Uttar
Pradesh Technical University Lucknow, U.P. India. Dr. Mishra has authored more than 28 referred journal and conference papers. His current research interests involve metamaterials structures and their applications. Currently, he is also serving as an active reviewer for IEEE Access, IEEE Sensors Journals, Progress In Electromagnetic Research, International Journal of RF and Microwave Computer-Aided Engineering, and International Journal of Electronics Engineering. Recently, he joined as a Review Editor on the Editorial Board of System and Test-Bed Design specialty section of Frontier in Communications and Networks.

Dr. Raghvendra Kumar CHAUDHARY is working as an Assistant Professor at the Department of Electronics Engineering, Indian Institute of Technology (Indian School of Mines), Dhanbad, India. He did his Ph.D. from the Indian Institute of Technology Kanpur, India in Jan. 2014, the M.Tech. degree from the Indian Institute of Technology (BHU), Varanasi, India, in 2009 and the B.Tech. degree from the University Institute of Engineering and Technology, Kanpur India, in 2007. Dr. Chaudhary has authored more than 130 referred journal and conference papers. He was the recipient of the International Travel Grant form CSIR, DST and IIT Kanpur, India. He was the recipient of the Best Student Paper Bronze Award at IEEE APACE, Malaysia in 2010 and also recipient of the Best Paper Award at ATMS, India in 2012. He is associate editor of IEEE Access, Member of IEEE and potential reviewer of many journals and conferences such as IEEE Transactions on Antennas \& Propagation, IEEE AWPL, IET MAP, IET Electronics Letters etc. His current research interests involve metamaterials, dielectric resonators, and computational electromagnetics. He is presently handling many research projects in the capacity of Principal Investigator sponsored from Indian funding agencies like SERB(DST), ISRO etc. He has also been featured interviewed by IET Electronics Letters, UK. 